\title{
An educational interventional study to compare conventional versus peyton's method in training medical students on antenatal examination skills
}

\author{
Dhivya Sethuraman ${ }^{1}$, S. Revwathy ${ }^{1}$, Prabha Thangaraj ${ }^{2 *}$
}

\begin{abstract}
${ }^{1}$ Department of Obstetrics and Gynaecology, ${ }^{2}$ Department of Community Medicine, Trichy SRM Medical College Hospital and Research Centre, Tiruchirapalli, Tamil Nadu, India
\end{abstract}

Received: 07 October 2020

Revised: 15 November 2020

Accepted: 01 December 2020

\section{*Correspondence:}

Dr. Prabha Thangaraj,

E-mail: prabha.thangaraj@gmail.com

Copyright: (c) the author(s), publisher and licensee Medip Academy. This is an open-access article distributed under the terms of the Creative Commons Attribution Non-Commercial License, which permits unrestricted non-commercial use, distribution, and reproduction in any medium, provided the original work is properly cited.

\begin{abstract}
Background: Introduction of competency based medical education in India has made it imperative to teach and assess clinical skills in a uniform manner. Antenatal Examination is one of the core competency under Obstetrics and Gynaecology. We need to use effective instructional methods to teach skills. In this study, we have compared Peyton's 'four step approach' with the conventional 'see one, do one' approach.

Methods: A quasi- randomized crossover study with educational intervention was done among 49 medical students. They were divided into two groups (A and B). Students of group A were first trained on Antenatal examination using Conventional method and evaluated. With a gap of one week, they were re-trained on the same skill using Peyton's method and re-evaluated again; the vice versa was for done in group B. Mann Whitney test was used to compare the difference in score between the two groups of students (A and B) and Wilcoxon Signed Ranks test was used to compare the student's perception of both teaching methods.

Results: The mean score obtained by students after the first training by Peyton's (24.08 \pm 2.31$)$ was greater than Conventional method $(20.32 \pm 3.59)$ which was found to be statistically significant $(\mathrm{Z}=-3.54, \mathrm{p}<0.5)$. Following the second training i.e crossover of the training technique, the marks obtained by both group of students were almost the same. Students perceived Peyton's methods to be more interesting, interactive, better understanding and recall over conventional.

Conclusions: Peyton's method was found to be superior over conventional method of training medical students in Antenatal examination.
\end{abstract}

Keywords: Antenatal examination, Peyton's method, Conventional method, Skills

\section{INTRODUCTION}

The introduction of competency based medical education (CBME) in India has made it imperative that medical graduates become competent in acquiring clinical and surgical skills throughout their residency. ${ }^{1}$ One such skill that the students need to acquire during rotation in Obstetrics and Gynaecology (OBG) is the Antenatal examination.
Bedside teaching is an invaluable method of training undergraduate students in Obstetrics and Gynaecology, especially in the context of interviewing and examining pregnant women which requires good communication skills along with an empathetic and caring attitude. It not only helps them learn and sharpen clinical skills, it also enables them to be better communicators and professionals in the future. $^{2}$ 
Though bedside teaching has become less popular in the western world, it still remains the most important method of teaching clinical examination to medical students in India. However, various studies published in the last two decades have proven beyond doubt that there is insufficient training of medical and surgical skills in medical graduates. ${ }^{3-5}$

Clinical skills training in medicine, traditionally employs the 'see one, do one, teach one', meaning that trainees, after observing a particular skill or procedure once, are expected to be capable of performing that procedure and to teach it as well to another trainee. ${ }^{6}$ Many argue that this teaching method is outdated as students are unable to effectively and confidently perform a skill or medical procedure after seeing it only once. ${ }^{7,8}$

Among various instructional approaches, the 'Peyton's 4step Approach' has become increasingly popular in teaching clinical and procedure skills.9-13 The '4-step Approach' consists of the following steps; Demonstration: the teacher performs the skill in real-time without any explanation; Deconstruction: the teacher performs the skill slowly, explaining every single step; Comprehension: the student explains whereupon the teacher performs every single step of the procedure; Execution: the student explains and simultaneously performs every step of the procedure.

Many of the studies published involving both methods are from the western world. Very few studies have been published from India. ${ }^{10-17}$ With CBME being implemented in our setting, this study will guide us to identify effective teaching methods for learning clinical skills. Objectives of the present study were to compare the skill achievement in Antenatal examination by using two educational teaching method: Conventional Vs Peyton's and to understand students and faculty of OBG department perceptions on both methods.

\section{METHODS}

The present quasi-randomized crossover study design comparing two types of educational intervention (Conventional Vs Peyton's) was conducted in the OBG Department of Trichy SRM Medical College Hospital and Research Centre during December to January 2020. On regular basis, around $150 \mathrm{MBBS}$ third year students were divided into 5 batches and attend clinical posting for four weeks in the OBG Department in rotation. Students of each batch are generally divided into two halves so that each student gets posted for two weeks at the OPD and two weeks in the ward. Those students posted first in the ward were grouped as group A while the others in group B. Two consequent batches of students (30 per batch) posted in the Department during the study period were included. Students absent during any one of the training or evaluation session were excluded. Ethical approved was obtained from the Institutional Ethics Committee prior to the study.
For the crossover study design, students of group A were first trained for antenatal examination using conventional method and evaluated on the same within the first week of their ward posting. During their second week of ward posting, they were trained on the same skill using Peyton's method and re-evaluated again; the vice versa was for done was group B during their ward posting i.e they were trained in Peyton's first followed by conventional. So eventually all students underwent training and assessment on both the teaching technique on the same skill. A likert scale of 1-10 was used to understand the students and faculties perception on both the techniques. The flow chart of the methodology is given in Figure 1.

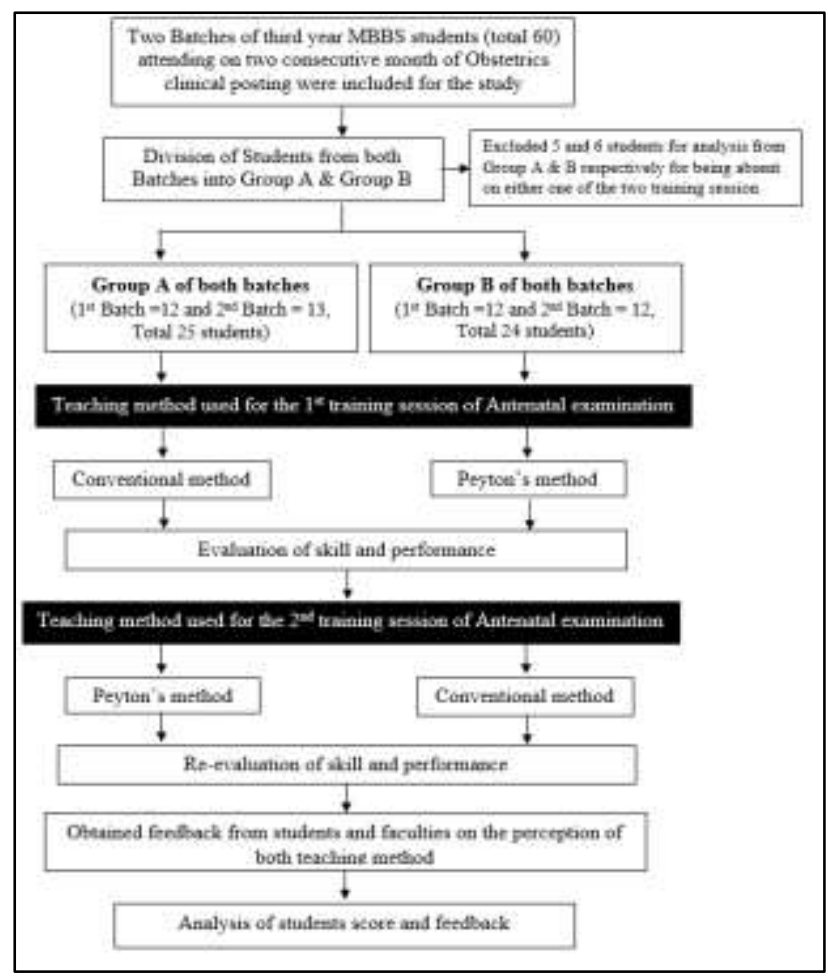

Figure 1: Flow chart depicting the methodology of study.

\section{Educational intervention}

A total of eight faculty in Obstetrics and Gynaecology were sensitized by the principal investigator to provide skill training in Antenatal examination using both methods (conventional and Peyton's) to maintain uniformity in the training session. For each of the teaching session, students were divided into smaller groups of three to four under the guidance of any one of the eight-faculty depending on their availability on that particular day. Each faculty was allotted one antenatal mother for the training session. Evaluation of students was done on the subsequent days and completed within a week of first training session. In the conventional teaching method the faculty demonstrated the skill following which the students were asked to perform the skills individually and evaluated. On the other hand, the 
Peyton's methods involved four steps (demonstration, deconstruction, comprehension and execution) with evaluation being the last step which was done separately for each student over a period of one week.

\section{Outcome evaluation}

A common scoring checklist was prepared to evaluate the student's skills following the training session to avoid discrepancies in scoring among the faculties. The skills checklist for Antenatal examination comprised of three section:

Section 1: general approach to the antenatal mother (soft skills). 7 steps were observed under this section such as greeting the mother, self-introduction, obtaining consent etc.

Section 2: inspection of the abdomen: This section included 5 steps such as position of umbilicus, observation of linea nigra, scars etc.

Section 3: palpation of the abdomen. The last section comprised of 18 steps such as palpation of fundal height, abdominal girth, the pelvic grips etc.
Section 1 was scored based of faculty observation of the students' performance while section 2 and 3 additionally required the students to explain their finding to the faculty. Each step done correctly was given one mark with a maximum attainable score of 30 . The students were graded using the same checklist for both the teaching techniques.

\section{Statistical analysis}

Data entry was done in Microsoft Excel and analysis in SSPS Version 21. The average scores obtained by students following the training session is expressed in mean and standard deviation. Mann Whitney test was used to compare the difference in score between the two groups of students (A and B) and Wilcoxon Signed Ranks test was used to compare the perception of the two teaching methods.

\section{RESULTS}

The mean score obtained by students after the first training by Peyton's $(24.08 \pm 2.31)$ was greater than that by Conventional method $(20.32 \pm 3.59)$ which was found to be statistically significant.

Table 1: Comparison of score obtained in antenatal examination skills among students of Group A (Conventional followed by Peyton's) and Group B (Peyton's followed by Conventional).

\begin{tabular}{|c|c|c|c|c|}
\hline Training session & Students group & Score (mean \pm SD) & $\mathbf{Z}$ & p value \\
\hline \multirow{2}{*}{$1^{\text {st }}$ session } & Group A (Conventional) & $20.32 \pm 3.59$ & \multirow{2}{*}{-3.54} & \multirow{2}{*}{$0.000 *$} \\
\hline & Group B (Peyton’s) & $24.08 \pm 2.31$ & & \\
\hline \multirow{2}{*}{$2^{\text {nd }}$ session } & Group A (Peyton's) & $28.48 \pm 2.63$ & \multirow{2}{*}{-0.33} & \multirow{2}{*}{0.738} \\
\hline & Group B (Conventional) & $28.30 \pm 2.40$ & & \\
\hline
\end{tabular}

SD- Standard Deviation, Z- Mann Whitney test, *- statistically significant

Table 2: Student's perception of using Conventional versus Peyton's methods for learning skills in antenatal examination.

\begin{tabular}{|lllll|}
\hline Perception & Conventional $($ mean \pm SD $)$ & Peyton's $($ mean \pm SD $)$ & $Z$ & P value \\
\hline Interest & $6.8 \pm 1.09$ & $9.47 \pm 0.73$ & -6.06 & $0.00^{*}$ \\
\hline Interactive & $6.18 \pm 1.55$ & $9.18 \pm 0.63$ & -6.03 & $0.00^{*}$ \\
\hline Time consuming & $3.80 \pm 1.39$ & $7.16 \pm 1.57$ & -5.86 & $0.00^{*}$ \\
\hline Understanding & $6.20 \pm 1.27$ & $9.37 \pm 0.80$ & -5.68 & $0.00^{*}$ \\
\hline Recall & $5.69 \pm 1.32$ & $8.71 \pm 1.35$ & -5.59 & $0.00^{*}$ \\
\hline Confidence & $5.69 \pm 1.32$ & $8.67 \pm 1.26$ & -6 & $0.00^{*}$ \\
\hline
\end{tabular}

Perception was assessed using Likert scale from 0 - 10 point; SD- Standard Deviation, Z- Wilcoxon signed ranks test, *- statistically significant

Following the second training i.e crossover of the training technique, the marks obtained by both students were almost the same (Table 1).

Students rated conventional and Peyton's method being interesting, interactive and understanding an average of 6 and 9 out of 10 respectively. Even recall and level of confidence in performing ANC examination was felt better in Peyton's method over conventional. Students perceived Peyton's method of teaching ANC examination was more time consuming (9/10) over conventional method (4/10). Table 2 shows the student's mean score of perception of both the teaching methods on a scale of 0 10. Faulty perception of student's recall and understanding was better for Peyton's (8/10) than conventional $(5 / 10)$. Student's interaction with faculty was almost similar for Peyton's (8.3/10) and conventional method (7.7/10) but was statistically significant. Faculty's found Peyton's method to be very time consuming (9/10) over conventional (5/10). Table 3 shows the faculty's mean score of perception of both the teaching methods on a scale of $0-10$. 
Table 3: Faculty perception of using Conventional versus Peyton's methods for learning skills in antenatal examination.

\begin{tabular}{|lllll|}
\hline Perception & Conventional $($ mean \pm SD $)$ & Peyton's $($ mean \pm SD $)$ & $Z$ & P value \\
\hline Student interaction & $7.7 \pm 1.1$ & $8.3 \pm 1.18$ & -1.89 & $0.059^{*}$ \\
\hline Time consuming & $5.2 \pm 1.1$ & $9.1 \pm 1.12$ & -2.21 & $0.027^{*}$ \\
\hline Student recall & $5.7 \pm 0.75$ & $8.3 \pm 1.06$ & -2.2 & $0.027^{*}$ \\
\hline Student confidence & $6.0 \pm 0.81$ & $7.5 \pm 1.12$ & -1.98 & $0.047^{*}$ \\
\hline Student understanding & $5.7 \pm 0.75$ & $8.0 \pm 0.75$ & -2.46 & $0.014^{*}$ \\
\hline Student interest & $5.7 \pm 0.75$ & $7.5 \pm 0.92$ & -1.6 & $0.037^{*}$ \\
\hline
\end{tabular}

Perception was assessed using Likert scale from 0 - 10 point; SD- Standard Deviation, Z- Wilcoxon signed ranks test, *- statistically significant.

\section{DISCUSSION}

Aim of this study was to investigate efficacy of two teaching methods in the acquisition of a clinical skill on Antenatal examination and also to understand students and teacher's perception of both methods. For ethical issues, each student underwent training using both methods, to enable them to acquire the skill better.

Our results revealed significant differences in performance between both groups following the first training session. Group B that underwent Peyton's method $(24.08 \pm 2.31)$ scored more than group A (20.32 \pm 3.59 ), thus supporting it to be a better teaching technique over the conventional method. Following the cross-over intervention (second training session) all the students of both group scored almost the same (28 out of 30). This also emphasizes the retention of skills after undergoing Peyton's method.

We believe a reason that the 'four step approach' is superior is that in step 3, the verbalization and subsequent instruction of the skill, led to a more profound cognitive processing and hence, to a better skills performance of the '4-step approach' group compared to the 'See One, Do One' group. This presumption is also supported by a previous study by Krautter et a who identified Step 3 as the most crucial part of Peyton's original '4-step approach'. ${ }^{14}$ Moreover with the ongoing COVID 19 pandemic, the Peyton's approach has also been used to deliver clinical skills remotely, using online platforms like Microsoft Teams. ${ }^{12}$

Previous studies have found a clear benefit of Peyton's '4-step approach' for complex motor skills, such as laparoscopic suturing and knot tying and in simulation based training. ${ }^{11,15}$ However, for relatively easy to learn motor skills like performing external chest compressions or the insertion of a laryngeal mask, no significant advantages could be found for Peyton's '4-step approach. ${ }^{16,17}$

We also found that the students favoured the Peyton's approach as an instructional method over the conventional method. They were more interested, were able to understand and recall better while performing antenatal examination. They believed that the 'four step approach' allowed for more interaction with the faculty and increased confidence while performing the skill.

The faculty involved also perceived that Peyton's was better than conventional approach in terms of generating student interest, improving understanding and recall and allowing for better interaction. However, both students and faculty felt that Peyton's approach was more time consuming when compared to the conventional method.

Even though Peyton's method is superior over the conventional method, there are some limitations in our study. Firstly, the cross-over of teaching technique was done in a gap of one week, which might affect the outcome. There is a need to understand up to what duration of time students are able to retain the skill following both the teaching method. Secondly, in most of the situation, the same antenatal mother was given to students for assessment purpose on the subsequent days. This may have a bias in student's response. But we expect this bias to be the same for group and thus not affecting the overall outcome of the study.

\section{CONCLUSION}

Most of the skills taught to medical students in OBG department is by conventional method of "see one, do one". The present study has compared this methods with Peyton's four step method which additionally includes teachers to perform the skills based on instructions given by the students. We found this method to be more effective over the conventional. Students and faculties perceived it to be more interesting and interactive with better understanding and recall of antenatal examination skills. The only drawback of Peyton's method is that it takes more time to teach ANC skills when compared to conventional method.

\section{ACKNOWLEDGMENTS}

The authors would like to thank all the staffs of OBG Department and students for lending their support in this study. They also appreciate the cooperation of Antenatal mothers for their patience. 
Funding: No funding sources

Conflict of interest: None declared

Ethical approval: The study was approved by the Institutional Ethics Committee

\section{REFERENCES}

1. Shah N, Desai C, Jorwekar G, Badyal D, Singh T. Competency-based medical education: An overview and application in pharmacology. Indian $\mathrm{J}$ Pharmacol. 2016;48(1):5-9.

2. Paritakul P. Optimising bedside teaching in obstetrics and gynaecology. Thai J Obstet Gynaecol. 2014;22:61-6.

3. Crumlish CM, Yialamas MA, McMahon GT. Quantification of bedside teaching by an academic hospitalist group. J Hosp Med. 2009;4:304-7.

4. Tallentire VR, Smith SE, Wylde K, Cameron HS. Are medical graduates ready to face the challenges of Foundation training? Postgrad Med J. 2011;87:5905.

5. Kotsis SV, Chung KC. Application of the 'see one, do one, teach one' concept in surgical training. Plast Reconstr Surg. 2013;131:1194-201.

6. Vozenilek J, Huff JS, Reznek M, Gordon JA. See One, Do One, Teach One: advanced technology in medical education. Acad Emerg Med. 2004;11:114954.

7. Mason WTM, Strike PW. Short communication see one, do one, teach one is this still how it works? A comparison of the medical and nursing professions in the teaching of practical procedures. Med Teach. 2003;25:664-6.

8. Rohrich RJ. See One, Do One, Teach One: an old adage with a new twist. Plast Reconstr Surg. 2006;118:257-8.

9. Peyton JWR. Teaching and learning in medical practice. Manticore Europe Ltd. 1998:171-180.

10. Dietsch G, Lübke C, Horst K, Simon M, Modabber A, Sönmez TT, et al. Peyton's four-step approach for teaching complex spinal manipulation techniques-a prospective randomized trial. BMC Med Education. 2016;16(1):284.

11. Romero P, Günther P, Kowalewski KF, Friedrich M, Schmidt MW, Trent SM, et al. Halsted's "see one, do one, and teach one" versus peyton's four-step approach: a randomized trial for training of laparoscopic suturing and knot tying. J Surg Education. 2018;75(2):510-5.

12. Khan H. An adaptation of Peyton's 4-stage approach to deliver clinical skills teaching remotely. Med Ed Publish. 2020:9.

13. Raghunath G, Francis YM, Karthikeyan G, Sankaran PK, Begum Z. A study on the effectiveness of Peyton's four-step approach in teaching procedural skill for MBBS students. Drug Invention Today. 2020;14(7):1226-8.

14. Werner HA, Nikendei C, Keifenheim K, Bosse HM, Lund F, Wagner R, et al. Best practice skills lab training vs. a see one, do one approach in undergraduate medical education: an RCT on students' long-term ability to perform procedural clinical skills. PloS one. 2013;8(9):e76354.

15. Tutdibi E, Gortner L, Volk T, Reus E. Simulationbased neonatal resuscitation training of medical students: is Peyton's 4-stage approach more effective than traditional 2-stage technique? In Molecular Cellular Pediatr. 2014;1(1):1.

16. Jenko M, Frangež M, Manohin A. Four-stage teaching technique and chest compression performance of medical students compared to conventional technique. Croat Med J. 2012;53:48695

17. Orde S, Celenza A, Pinder M. A randomised trial comparing a 4-stage to 2-stage teaching technique for laryngeal mask insertion. Resuscitation. 2010;81(12):1687-91.

Cite this article as: Sethuraman D, Revwathy $S$, Thangaraj P. An educational interventional study to compare conventional versus peyton's method in training medical students on antenatal examination skills. Int J Reprod Contracept Obstet Gynecol 2021;10:198-202. 